\title{
Acute Q Fever Diagnosed by Metagenomic Next- generation Sequencing and Clinically Compared With Scrub Typhus
}

Xi Liu

Sun Yat-sen University Fifth Affiliated Hospital

\section{Ziliang Lin}

Sun Yat-sen University Fifth Affiliated Hospital

Hongqiong Zhu

Sun Yat-sen University Fifth Affiliated Hospital

Gongqi Chen

Sun Yat-sen University Fifth Affiliated Hospital

\section{Pengyuan He}

Sun Yat-sen University Fifth Affiliated Hospital

\section{Mingxing Huang}

Sun Yat-sen University Fifth Affiliated Hospital

Jinyu Xia ( $\nabla$ xiajinyu@mail.sysu.edu.cn )

Sun Yat-sen University Fifth Affiliated Hospital

\section{Research}

Keywords: Acute Q fever, Scrub typhus, Metagenomic next-generation sequencing, Clinical Characteristic, Diagnosis

Posted Date: July 28th, 2020

DOI: https://doi.org/10.21203/rs.3.rs-47623/v1

License: (c) (1) This work is licensed under a Creative Commons Attribution 4.0 International License. Read Full License 


\section{Abstract}

Background: $C$. burnetti, the causative agent of $Q$ fever, is considered a potential threat as a biological weapon because of highly infectious and pathogenic. There was an outbreak of Q fever in Zhuhai, P.R. China between December, 2018 and March 2019, although Zhuhai was not the endemic area of Q fever. 46 patients can be detected $\mathrm{C}$. burnetti by metagenomic next-generation sequencing (mNGS). There are many similarities between acute $\mathrm{Q}$ fever and scrub typhus in clinical manifestations.

Methods: We analyze the differences of clinical manifestations and serological between 46 patients with acute $\mathrm{Q}$ fever and 100 patients with scrub typhus. The general information of patients including gender, age, basic disease, days from disease onset and clinical manifestations were evaluated.

Results: Their mean age of acute Q fever was $43.6 \pm 11.8$ (ranging from 32 to 55 years old), younger than scrub typhus patients (53.9 \pm 12.7 , ranging from 41 to 67 years old) $(P<0.001)$. Males are more susceptible to $C$. burnetti. There were 45 males $(97.8 \%)$ in acute $Q$ fever patients and 59 males $(59.0 \%)$ in scrub typhus patients $(P<0.001)$. Compared with scrub typhus, patients with acute $\mathrm{Q}$ fever are more prone to present sore throat $(P=0.003)$, abnormal liver function $(P<0.001)$ and elevated levels of procalcitonin $(P<0.001)$. Meanwhile, skin rash $(P<0.001)$, eschar $(P<0.001)$, lymphadenopathy $(P<0.001)$, leukocytosis $(P<0.001)$, thrombocytopenia $(P=0.003)$, eosinophils reducing or disappearing $(P=0.002)$ and pulmonary involvement on chest imaging $(P=0.003)$ were more common in scrub typhus. There was significant difference between the two groups $(P<0.001)$. Days from minocycline treatment to defervescence in acute $\mathrm{Q}$ fever (1.82 \pm 1.357 , ranging from 0.5 to 3.2 days) were shorter than scrub typhus $(2.85 \pm 2.801$, ranging from 0.0 to 5.7 days) $(P=0.008)$.

Conclusions: mNGS is helpful to early diagnosis of acute Q fever. Sex, age, serologic test and physical examination are important in the differentiation of acute $Q$ fever from scrub typhus in Zhuhai, China.

\section{Background}

Q fever in human beings has been described in countries around the world, except New Zealand[1]. As we all know, Coxiella burnetii( $C$. burnetti), which causes $\mathrm{Q}$ fever, is a highly infectious agent and can resist extremes of temperature, $\mathrm{pH}$, and desiccation, which is essential for survival in the harsh environment[1]. C. burnetti can be disseminated in an aerosolized form to cause chronic $\mathrm{Q}$ fever, sometimes fatal disease. Thus $C$. burnetti was considered a potential threat as a biological weapon in 1942 due to the highly infectious and pathogenic[2]. It is also reported that Russia fabricated Q fever as a biological weapon[2]. In addition, there were several Q fever outbreaks were reported in military personnel[2]. In the Border Army of Ali area of Tibet, there was a resurgence of Q fever in 1968[3]. However, Q fever has long been a neglected infectious disease so many aspects of the disease in China, including its diagnosis to clinical manifestations, are unknown, leading to misdiagnosis and missed diagnosis easily. Besides, only a few research laboratories are engaged in the research of $Q$ fever[4]. There is an urgent need for a more detailed understanding of $\mathrm{Q}$ fever. 
There were 46 patients diagnosed with acuter Q fever by metagenomic next-generation sequencing (mNGS) in our hospital in Zhuhai, China. Metagenomics for clinical applications derives its roots from the use of core technology in the early 2000s[5]. By comparing the microbial database and analyzing the intelligent algorithm, this technique can obtain the species information of the suspected pathogenic microorganisms, which has great potential utility in the diagnosis of infectious disease. Some successes using this technology include the case of neuroleptospirosis in a 14-year-old critically ill boy with meningoencephalitis[6]. Also, mNGS was used for the clinical diagnosis of human infectious endophthalmitis caused by pseudorabies virus, as successful diagnosis peompted appropriate targeted antibiotic treatment and eventual recovery of the patient[7]. Compared with traditional molecular detection, mNGS has the characteristics of high throughput, low-volume sample, rapid and accurate[8], which can be used as a supplement to traditional detection methods.

Acute $\mathrm{Q}$ fever and scrub typhus belong to rickettsial diseases, and scrub typhus occurs with sporadic epidemics in Zhuhai. There are many similarities between acute $Q$ fever and scrub typhus in clinical manifestations. Acute $\mathrm{Q}$ fever, a disease caused by the bacteria $C$. burnetti[9], presents various clinical manifestations such as fever, chills, headache, muscle aches and varying degrees of pneumonia and hepatitis[10]. Scrub typhus is a common zoonotic disease in humans, caused by Orientia tsutsugamushi(O.tsutsugamushi) infection[11]. Its major clinical feature is high fever, eschar or ulcer, lymphadenectasis and rash found at the inoculation site of the chigger bite[12, 13]. However, not all the patients of scrub typhus can be found the distinctive eschar. At present, acute $\mathrm{Q}$ fever is diagnosed through etiology test and serological examination, which include complement fixation test (CFT)[14], enzyme-linked-immunosorbent assay (ELISA)[15], indirect immune-fluorescence test (IFT)[16], cell culture[17], polymerase chain reaction(PCR)[18] and so on. The diagnosis of scrub typhus is always diagnosed based on serological tests and molecular assays[19], such as the indirect immunofluorescence assay (IFA)[20] and PCR[21]. However, the above methods are too expensive and complicated to achieve. Without the techniques for pathogenic detection, it is difficult to differentiate acute $Q$ fever and scrub typhus in clinical practice. To assist early diagnosis for clinical, we analyze the differences of clinical manifestations and serological between patients with acute $Q$ fever and scrub typhus.

\section{Study Subject And Methods \\ 2.1. Study subject}

The medical records of patients diagnosed with acute $Q$ fever and scrub typhus at The Fifth Affiliated Hospital of Sun Yat-sen University, which is a tertiary teaching hospital located in the Zhuhai region, from October 2014 to March 2019 were retrospectively reviewed. There were 46 acute Q fever patients whose blood samples can detect $C$. burnetti and 100 scrub typhus patients. The general information of patients including gender, age, basic disease, days from disease onset and clinical manifestations were evaluated.

\subsection{Methods of mNGS}


Serologic assessments using mNGS were performed in the contract laboratory of BGI. Blood samples were collected after hospital visit. And within 48 hours, the results could be sent to our OA from the contract laboratory of BGI after nucleic acid extraction, library construction and sequencing, data treatment and analysis. The methods of mNGS is as follows: 1) sample collection: blood samples were collected in accordance under strict aseptic procedures, snap frozen and stored at $-80^{\circ} \mathrm{C}$ before administering antibiotics treatment. 2) nucleic acid extraction: $0.6 \mathrm{ml}$ plasma was obtained after centrifugation at $2000 \mathrm{~g}$ for $10 \mathrm{~min}$ and again centrifuged at $16000 \mathrm{~g}$ for $10 \mathrm{~min}$. After two centrifugations, $0.3 \mathrm{ml}$ supernatant was collected, which used for nucleic acid extraction with the TIANamp Micro DNA Kit (DP316, Tiangen Biotech, Beijing, China). 3) library construction and sequencing: the DNA libraries were constructed through end repair, end-repaired adapter added overnight and amplification by PCR. 4) data treatment and analysis: in order to generate high-quality sequencing data, the raw data was initially screened to remove low quality reads and shorter reads. To eliminate influence from human sequences, sequence data were mapped against the human reference genome (hg19) with the Burrows-Wheeler Aligner, formidable alignment tool. Finally, the remaining data were aligned to Microbial Genome Database, which includes bacteria, viruses, fungi, and protozoa to distinguish the pathogenic sequences.

\subsection{The inclusion criteria of acute $Q$ fever and scrub typhus}

Acute $Q$ fever was considered positive when at least 1 read was mapped to either the species or genus level due to the difficulty of DNA extraction, standard procedures and a low possibility for contamination. 46 patients whose blood samples can detect $C$. burnetti, were diagnosed with acute $\mathrm{Q}$ fever by mNGS.

The diagnosis of scrub typhus is based on the Technical Guides for Prevention and Control of Scrub Typhus by the Chinese Center for Disease Control and Prevention. The clinical diagnosis was mainly based on some of the following clinical features and signs:1) Epidemiological exposure history within 3 weeks prior to the onset during the epidemic season, 2) fever, 3) lymphadenectasis, 4) skin rash, and 5) specific eschar or ulcer. Clinically confirmed cases are defined by meeting at least following criteria ' 1 , 2, 3 and 5'or '1, 2, 4 and 5'after excluding other diseases with similar clinical manifestations.

\subsection{Statistical Analysis}

T test was used for continuous variables of the normal distribution, and non-parametric test was used for variables of non-normal distribution. Chi-square test or Fisher's exact test was used for categorical variables. All statistical analyses were done using the Statistical Package for the Social Sciences (SPSS) for Windows, version 20 (IBM Corp., Armonk, NY, USA). $P<0.05$ was considered statistically significant.

\section{Results}

\subsection{The results of $\mathrm{mNGS}$ in acute $\mathrm{Q}$ fever}

The mNGS testing results of 46 acute $Q$ fever patients were shown in Fig. 1. According to Fig. 1, we can see that all 46 patients can be detected $C$. burnetti, which sequences number ranged from 2 to 824 . 


\subsection{Acute $\mathrm{Q}$ fever and scrub typhus fever in epidemiology}

There was an outbreak of $\mathrm{Q}$ fever between December and March, the maximum number occurred during January followed by February (Fig. 2). There were 30 patients were diagnosed as having acute $\mathrm{Q}$ fever in January. Besides, our study results demonstrate that the temporal distribution of reported scrub typhus cases followed a bimodal seasonal pattern characterized by two yearly peaks observed between May and December. We can see that the number of scrub typhus cases demonstrated a large peak in May or June, and then revealed anther large peak in October with a continuous decrease thereafter. Scrub typhus cases were diagnosed in all months tested except January and April. However, acute Q fever cases only occurred from November to March during the research period.

\subsection{Differences in clinical characteristics and complication between cases of acute $\mathrm{Q}$ fever and scrub typhus}

The mean age of patients with acute $Q$ fever was $43.6 \pm 11.8$ (ranging from 32 to 55 years old), younger than scrub typhus patients $(53.9 \pm 12.7$, ranging from 41 to 67 years old) $(P<0.001)$. Males are more susceptible to $C$. burnetti There were 45 males (97.8\%) in acute $Q$ fever patients and 59 males (59.0\%) in scrub typhus patients $(P<0.001)$. Fatty liver was more common in acute $\mathrm{Q}$ fever $(47.7 \% \mathrm{vs} 16.0 \%, P=$ 0.001). There was no difference between the two groups in the following basic disease: hypertensive disease, diabetes, coronary heart disease, chronic obstructive pulmonary disease, hepatitis B, pulmonary tuberculosis, malignancy, and dyslipidemia. $(P>0.05)$ (Table 1). 
Table 1

Demographic statistics and history of patients with acute $\mathrm{Q}$ fever and scrub typhus

\begin{tabular}{|c|c|c|c|c|}
\hline & $\begin{array}{l}\text { acute } Q \\
\text { fever } \\
(\mathrm{N}=46) \\
\mathrm{n}(\%) \text { or } \mathrm{M} \pm \\
\mathrm{SD}\end{array}$ & $\begin{array}{l}\text { scrub } \\
\text { typhus } \\
(\mathrm{N}=100) \\
\mathrm{n}(\%) \text { or } \mathrm{M \pm} \\
\text { SD }\end{array}$ & $\begin{array}{l}P \\
\text { value }\end{array}$ & OR $(95 \% \mathrm{Cl})$ \\
\hline \multicolumn{5}{|l|}{ demographic characteristics } \\
\hline $\begin{array}{l}\text { Days from disease onset to the visit } \\
\text { time } \pm S D\end{array}$ & $5.13 \pm 1.45$ & $7.22 \pm 3.43$ & 0.000 & $1.263-2.911$ \\
\hline age $\pm S D$ & $\begin{array}{l}43.56 \pm \\
11.83\end{array}$ & $\begin{array}{l}53.89 \pm \\
12.78\end{array}$ & 0.000 & $5.926-14.723$ \\
\hline male & 45(97.82) & $59(59.00)$ & 0.000 & $\begin{array}{l}0.032(0.004- \\
0.241)\end{array}$ \\
\hline \multicolumn{5}{|l|}{ history } \\
\hline hypertensive disease & $7(15.22)$ & 16(16.00) & 0.904 & $\begin{array}{l}0.942(0.359- \\
2.476)\end{array}$ \\
\hline diabetes & $4(8.70)$ & $17(17.00)$ & 0.283 & $\begin{array}{l}0.465(0.147- \\
1.470)\end{array}$ \\
\hline COPD & $0(0.00)$ & $1(1.00)$ & 1.000 & NA \\
\hline coronary heart disease & $0(0.00)$ & $6(6.00)$ & 0.177 & NA \\
\hline malignancy & $0(0.00)$ & $3(3.00)$ & 0.552 & NA \\
\hline hepatitis B & 8(17.39) & $15(15.00)$ & 0.713 & $\begin{array}{l}1.193(0.466- \\
3.052)\end{array}$ \\
\hline fatty liver & $21(47.73)$ & 16(16.00) & 0.001 & $\begin{array}{l}3.880(1.737- \\
8.671)\end{array}$ \\
\hline hepatic cirrhosis & $0(0.00)$ & $2(2.00)$ & 1.000 & NA \\
\hline dyslipidemia & $1(2.17)$ & $8(8.00)$ & 0.322 & $\begin{array}{l}0.256(0.031- \\
2.106)\end{array}$ \\
\hline pulmonary tuberculosis & $2(4.35)$ & $2(2.00)$ & 0.794 & $\begin{array}{l}2.227(0.304- \\
16.326)\end{array}$ \\
\hline chronic kidney disease & $0(0.00)$ & $3(3.00)$ & 0.552 & NA \\
\hline
\end{tabular}

Both acute $\mathrm{Q}$ fever and scrub typhus presented high fever. Their mean temperature of acute $\mathrm{Q}$ fever was $39.6 \pm 0.42^{\circ} \mathrm{C}$ (ranging from 39.18 to $40.02^{\circ} \mathrm{C}$ ), higher than scrub typhus patients $\left(39.39 \pm 0.65^{\circ} \mathrm{C}\right.$, 
ranging from 38.7 to $\left.40.04^{\circ} \mathrm{C}\right)(P=0.044)$. Compared with acute $\mathrm{Q}$ fever patients, eschar $(P<0.001)$, skin rash $(P<0.001)$, lymphadenopathy $(P<0.001)$, were more common in scrub typhus patients. However, there is no difference in chill, headache, muscle aches, fatigue, cough or poor appetite between the two groups. ( $P \otimes 0.05)$. It is noteworthy that patients with acute $\mathrm{Q}$ fever are more prone to present sore throat $(P$ $=0.003$ ) than patients with scrub typhus (Table 2).

Table 2

Differences in clinical symptoms and signs of acute $\mathrm{Q}$ fever and scrub typhus

\begin{tabular}{|c|c|c|c|c|}
\hline & $\begin{array}{l}\text { Acute } Q \text { fever } \\
(N=46) \\
n(\%) \text { or } M \pm S D\end{array}$ & $\begin{array}{l}\text { Scrub typhus } \\
(N=100) \\
n(\%) \text { or } M \pm S D\end{array}$ & $P$ value & OR $(95 \% \mathrm{Cl})$ \\
\hline mean temperature $\pm S D$ & $39.57 \pm 0.42$ & $39.39 \pm 0.65$ & 0.044 & $-0.359-(-0.005)$ \\
\hline eschar & $0(0.00)$ & $100(100.00)$ & 0.000 & NA \\
\hline skin rash & $0(0.00)$ & $40(40.00)$ & 0.000 & NA \\
\hline lymphadenopathy & $0(0.00)$ & $29(29.00)$ & 0.000 & NA \\
\hline chill & $34(79.91)$ & $64(64.00)$ & 0.236 & $0.627(0.289-1.361)$ \\
\hline shiver & $28(60.87)$ & $46(46.00)$ & 0.095 & $0.548(0.269-1.115)$ \\
\hline headache & $37(80.44)$ & 73(73.00) & 0.333 & $0.658(0.281-1.541)$ \\
\hline muscle aches & $22(47.83)$ & $49(49.00)$ & 0.895 & $1.048(0.510-2.360)$ \\
\hline fatigue & $26(56.52)$ & $61(61.00)$ & 0.608 & $1.203(0.593-2.442)$ \\
\hline cough & $5(10.87)$ & $15(15.00)$ & 0.500 & $1.447(0.492-4.255)$ \\
\hline expectoration & $4(8.70)$ & $4(4.00)$ & 0.443 & $0.438(0.104-1.833)$ \\
\hline nausea & $4(8.70)$ & $6(6.00)$ & 0.805 & $0.670(0.180-2.500)$ \\
\hline vomit & $3(6.52)$ & $9(9.00)$ & 0.855 & $1.418(0.365-5.501)$ \\
\hline poor appetite & 12(26.09) & $17(17.00)$ & 0.201 & $0.580(0.251-1.344)$ \\
\hline throat & 13(28.26) & $9(9.00)$ & 0.003 & $0.251(0.098-0.642)$ \\
\hline
\end{tabular}


Table 3

Differences in laboratory results between cases of acute Q fever and scrub typhus

\begin{tabular}{|c|c|c|c|c|}
\hline & $\begin{array}{l}\text { Acute } Q \text { fever }(N= \\
46) \\
n(\%)\end{array}$ & $\begin{array}{l}\text { Scrub typhus }(\mathrm{N}= \\
100) \\
\mathrm{n}(\%)\end{array}$ & $\begin{array}{l}P \\
\text { value }\end{array}$ & OR $(95 \% \mathrm{Cl})$ \\
\hline $\begin{array}{l}\text { WBC }>9.5 \times \\
10^{9} / \mathrm{L}\end{array}$ & $0(0.00)$ & $23(23.00)$ & 0.000 & $N A^{*}$ \\
\hline $\begin{array}{l}\text { WBC }<4.0 \times \\
109 / L\end{array}$ & $7(15.22)$ & 13(13.00) & 0.717 & $1.201 .(0.445-3.244)$ \\
\hline $\mathrm{NEU}>6.3 \times 10^{9} / \mathrm{L}$ & $1(2.17)$ & $34(34.00)$ & 0.000 & $\begin{array}{l}23.182(3.062- \\
175.515)\end{array}$ \\
\hline $\begin{array}{l}\text { EOS }<0.02 \times \\
10^{9} / \mathrm{L}\end{array}$ & $26(56.52)$ & $81(81.00)$ & 0.002 & $3.279(1.522-7.067)$ \\
\hline $\begin{array}{l}\mathrm{PLT}<125 \times \\
10^{9} / \mathrm{L}\end{array}$ & $15(32.61)$ & $59(59.00)$ & 0.003 & $2.974(1.427-6.196)$ \\
\hline ALT > 100U/L & $32(69.57)$ & 42(42.00) & 0.002 & $3.156(1.501-6.636)$ \\
\hline AST $>80 \mathrm{U} / \mathrm{L}$ & $28(60.87)$ & $53(53.00)$ & 0.374 & $1.379(0.678-2.807)$ \\
\hline $\mathrm{T}-\mathrm{BIL}>24 \mathrm{umol} / \mathrm{L}$ & $6(13.04)$ & 11(11.00) & 0.721 & $0.824(0.285-2.384)$ \\
\hline $\mathrm{Y}-\mathrm{G} \mathrm{T}^{\mathrm{a}}>60 \mathrm{U} / \mathrm{L}$ & $22(88.00)$ & $42(60.87)$ & 0.025 & $0.212(0.058-0.778)$ \\
\hline $\mathrm{ESR}^{\mathrm{b}}>15 \mathrm{~mm} / \mathrm{H}$ & $27(64.27)$ & 42(77.78) & 0.145 & $1.944(0.791-4.782)$ \\
\hline $\mathrm{CRP}^{\mathrm{C}}>8.2 \mathrm{mg} / \mathrm{L}$ & $44(97.78)$ & $48(94.12)$ & 0.701 & $0.364(0.036-3.626)$ \\
\hline $\mathrm{PCT}^{\mathrm{d}}>0.5 \mathrm{ng} / \mathrm{ml}$ & $43(93.48)$ & $40(55.56)$ & 0.000 & $0.087(0.025-0.307)$ \\
\hline $\mathrm{SCr}>97 \mathrm{umol} / \mathrm{L}$ & $7(15.22)$ & $16(16.00)$ & 0.904 & $1.061(0.404-2.788)$ \\
\hline
\end{tabular}

Table 4 shows the renal insufficiency, myocarditis, sepsis, acute respiratory distress syndrome, meningitis, Guillain-Barre syndrome, and gastrointestinal bleeding had no difference between the two groups $(P>0.05)$, but the rate of hepatitis $(P=0.002)$, pneumonia $(P=0.04)$, pleurisy $(P=0.003)$ were lower in acute $Q$ fever than in scrub typhus. 
Table 4

differences in complications between tsutsugamushi and acute $Q$ fever

\begin{tabular}{|c|c|c|c|c|}
\hline & $\begin{array}{l}\text { Acute } Q \text { fever }(N= \\
46) \\
n(\%)\end{array}$ & $\begin{array}{l}\text { Scrub typhus }(\mathrm{N}= \\
100) \\
\mathrm{n}(\%)\end{array}$ & $\begin{array}{l}P \\
\text { value }\end{array}$ & OR $(95 \% \mathrm{Cl})$ \\
\hline toxic hepatitis & $45(97.83)$ & $75(75.00)$ & 0.002 & $\begin{array}{l}15.000(1.965- \\
114.515)\end{array}$ \\
\hline pneumonia $^{a}$ & $3(6.67)$ & $20(22.47)$ & 0.040 & $\begin{array}{l}4.058(1.137- \\
14.489)\end{array}$ \\
\hline pleurisy $^{a}$ & $5(11.11)$ & $31(34.83)$ & 0.003 & $\begin{array}{l}4.276(1.531- \\
11.940)\end{array}$ \\
\hline renal insufficiency & $5(10.87)$ & $16(16.00)$ & 0.412 & $0.640(0.219-1.869)$ \\
\hline myocarditis & $0(0)$ & $1(1.00)$ & 1.000 & NA \\
\hline sepsis & $0(0)$ & $4(4.00)$ & 0.308 & NA \\
\hline ARDS & $0(0)$ & $3(3.00)$ & 0.552 & NA \\
\hline meningitis & $0(0)$ & $3(3.00)$ & 0.552 & NA \\
\hline GBS & $0(0)$ & $1(1.00)$ & 1.000 & NA \\
\hline $\begin{array}{l}\text { digestive } \\
\text { tracthemorrhage }\end{array}$ & $0(0)$ & $1(1.00)$ & 1.000 & NA \\
\hline
\end{tabular}

ARDS = Acute Respiratory Distress Syndrome; GBS = Guillain-Barre syndrome; NA = not available; a: acute $Q$ fever $n=45$, scrub typhus $n=89$.

\subsection{Differences in laboratory detection between cases of acute $Q$ fever and scrub typhus}

Compared with scrub typhus patients, acute $Q$ fever patients were more likely to show up normal white blood cell counts $(P<0.001)$, elevated alanine aminotransferase (ALT) $>100 \mathrm{U} / \mathrm{L}(P=0.002), \gamma$-glutamine transferase $(\gamma-\mathrm{GT})>60 \mathrm{U} / \mathrm{L}(P=0.025)$, procalcitonin $(\mathrm{PCT})>0.5 \mathrm{ng} / \mathrm{ml}(P<0.001)$ than scrub typhus. However, there were more scrub typhus patients had leukocytosis $(P<0.001)$, thrombocytopenia $(P=$ $0.003)$, eosinophils reducing or disappearing $(P=0.002)$ than acute $\mathrm{Q}$ fever patients. In addition, there were no differences between the two subgroups in alanine aminotransferase (AST) range.

\subsection{Response to minocycline treatment in cases of acute $Q$ fever and scrub typhus}

There was a significant difference between acute $Q$ fever and scrub typhus in terms of response to minocycline treatment. Days from minocycline treatment to defervescence in acute $Q$ fever $(1.82 \pm 1.36$, ranging from 0.46 to 3.18 days) were shorter than scrub typhus $(2.85 \pm 2.80$, ranging from 0.05 to 5.65 days) $(P=0.008)$. The total hospital day of acute $Q$ fever was $5.33 \pm 2.73$ (ranging from 2.60 to 8.06 
days), shorter than scrub typhus patients $(8.93 \pm 5.46$, ranging from 3.47 to 14.39 days $)(P<0.001)$ (Table $5)$.

\section{Table 5}

Response to minocycline treatment in cases of acute $\mathrm{Q}$ fever and scrub typhus.

\begin{tabular}{|c|c|c|c|c|}
\hline & $\begin{array}{l}\text { acute } Q \\
\text { fever } \\
(\mathrm{N}=46)\end{array}$ & $\begin{array}{l}\text { scrub } \\
\text { typhus } \\
(N=100)\end{array}$ & $\begin{array}{l}P \\
\text { value }\end{array}$ & OR $(95 \% \mathrm{Cl})$ \\
\hline & $M \pm S D$ & $M \pm S D$ & & \\
\hline Total hospital day & $5.33 \pm 2.73$ & $8.93 \pm 5.46$ & 0.000 & $\begin{array}{l}2.264- \\
4.943\end{array}$ \\
\hline $\begin{array}{l}\text { Days from disease onset to minocycline } \\
\text { treatment }\end{array}$ & $5.62 \pm 1.50$ & $7.63 \pm 3.35$ & 0.000 & $\begin{array}{l}1.156- \\
2.853\end{array}$ \\
\hline $\begin{array}{l}\text { Days from the visit time to minocycline } \\
\text { treatment }\end{array}$ & $0.72 \pm 1.00$ & $0.56 \pm 1.04$ & 0.412 & $\begin{array}{l}-0.563- \\
0.232\end{array}$ \\
\hline Days from the visit time to defervescence & $2.26 \pm 1.54$ & $3.44 \pm 2.86$ & 0.003 & $\begin{array}{l}0.424- \\
1.950\end{array}$ \\
\hline $\begin{array}{l}\text { Days from minocycline treatment to } \\
\text { defervescence }\end{array}$ & $1.82 \pm 1.36$ & $2.85 \pm 2.80$ & 0.008 & $\begin{array}{l}0.271- \\
1.791\end{array}$ \\
\hline
\end{tabular}

\section{Discussion}

Our research shows that an oubreak of human Q fever occurred in Zhuhai. The main source of infection for $Q$ fever was infected livestock, including sheep, cattle and goats[1]. When animals were infected with Coxiella burnetii, most of them have no obvious symptoms. Thus the infected animals can spread the $C$. burnetti when they give birth or were slaughtered. Relevant research shows that wind can carry the $C$. burnetti for miles[22]. People may get sick when they help animals give bith or breathe in the dust mixed with $C$. burnetti. Many cases illustrate people may get sick although low respiratory infective dose. However $\mathrm{Q}$ fever is frequently viewed as an unimportant disease because the symptoms are non-specific. The majority of patients in this study is male. Past research revealed that male acute $\mathrm{Q}$ fever patients evidently seem more at risk for direct $C$. burnetti than female[2, 23]. Unfortunately, misdiagnosis of acute $\mathrm{Q}$ fever and other febrile diseases is frequent because symptoms are often vague and nonspecific. Once infected, the soldier may develop several symptoms that, if misdiagnosed and spread, can cause a significant impact on the entire barracks[24]. Furthermore, $Q$ fever is not a reportable disease and probably largely misdiagnosed on account of lack of diagnostic technique in China. As mentioned above, $\mathrm{Q}$ fever manifests in acute form, causing flu-like symptoms such as fever, headache, muscle aches,and chills, leading to misdiagnosis.If an appropriate antibiotic is not timely administered, acute $\mathrm{Q}$ fever can become chronic $Q$ fever, which leads to low quality of life or even death. It is time to pay more attention to 
Q fever. In this study, we used mNGS of a blood sample from the patient and detected $C$. burnetti, allowing us to diagnose acute $\mathrm{Q}$ fever. Figure 1 shows that $C$. burnetti can be detected by mNGS. Once the infection caused by $C$. burnetti had been diagnosed, doctors put them on minocycline as clinical empirical therapy. Surprisingly, the clinical symptoms were improved, which further strengthens our diagnosis is correct. It proves the issue that $\mathrm{mNGS}$ is helpful to the early diagnosis of acute $\mathrm{Q}$ fever. It is worth noting that mNGS, which is independent of traditional microbial cultivation and direct sequencing, is a rapid and objective assay to detect various pathogens in clinical samples(viruses, bacteria, fungi, and parasites)[25]. Also, mNGS can greatly reduce the detection time, providing the results less than 48 hours, and avoid the impact of culture conditions and antimicrobial use, which is especially suitable for the diagnosis of critically ill and incurable diseases[26-28]. There is no bias in mNGS, because no primer and nucleic acid were used in mNGS, improving the diagnosis of infectious diseases. In this study, we used $\mathrm{mNGS}$ to explore pathogens and were able to cure the patient.

According to this study, the highest incidence of acute $Q$ fever occurred in January and February, while the highest incidence of scrub typhus occurred in May to October, which conforms to the summer-autumn type in south China[29, 30]. However, there was a rare outbreak of Q fever in Zhuhai, P.R. China, which may be biased. Thus, we needed to increase the size of the population for our study.

45 patients of acute $Q$ fever were male, and the mean age of acute $Q$ fever was 45 years (range 32-55), with a male-to-female ratio of $97.8 \%$. However, only $59.0 \%$ patients of scrub typhus were male. This is supported by the literature that men are at higher risk of infection by $C$. burnetti than women[31]. Some studies have found the protective effects of estrogen against $C$. burnetti infection[32, 33], thus the symptoms were significantly more intense in men than in women. Also, the expression of the Per2 gene was increased in men with acute $Q$ fever but not in women[34], which provides a reasonable explanation of the sexual discrepancy in $\mathrm{Q}$ fever. The younger they are, the more attention to their health conditions they pay, so that more of them consulted a physician and were diagnosed. Due to the timely treatment of minocycline, the patients of acute $\mathrm{Q}$ fever spent less time for the body temperature to return to normal.

There were no patients of acute $Q$ fever exhibited eschar, skin rash and lymphadenopathy during the treatment process. On the contrary, in scrub typhus, eschar was found in $100.0 \%$ of the patients, skin rash in $40.0 \%$, lymphadenopathy in $29.0 \%$. Eschar, the characteristic manifestations by chigger bite, is found in $7 \%-97 \%$ patients[35]. Possible reasons for these discordant results that all the scrub typhus patients in this study show the characteristic eschar may be differences in diagnostic criteria. On the other hand, O.tsutsugamushi is transmitted to human through trombiculid bite[11, 12], and $C$. burnetti infection is transmitted by inhaling of aerosol through the respiratory tract $[9,36]$, which allows direct contact with arthropods to be avoided. Dendritic cells and monocytes may be the target cells of Orientia tsutsugamushi that can cause vasculitis and reticuloendothelial cell proliferation[37, 38], which may be cause skin rash and lymphadenopathy. In contrast, $C$. burnettican invade the monocytes and macrophages, leading to granuloma formation[39-41].Based on the above-mentioned findings, we emphasize the meticulous physical examination to find the characteristic presentation when a febrile patient comes. 
Acute $Q$ fever patients in many areas mainly presented with pneumonia rather than toxic hepatitis[42, 43]. However, our results showed that toxic hepatitis is the main form of presentation of Q fever in Zhuhai, with abnormal transaminase and $y-G T$. Previous literature has shown that hepatitis rather than pneumonia is the predominant presentation of acute $Q$ fever in southern Taiwan[44]. The exact reason for this is unknown. It is speculated that the symptom may be associated with the different $C$. burnetti genotypes in different regions[45].Univariate analysis showed that leukocytosis, thrombocytopenia, eosinophils reducing or disappearing and pulmonary involvement on chest imaging were more common in scrub typhus.

Previous findings have shown that PCT is a trustful biomarker for bacterial infection, but not viral infection[46-48]. However, according to research by Rule,J.A. et al, PCT cannot be used for the diagnosis of bacterial infection in acute hepatic failure, whose level is associated with pathological severity[49]. The rise of PCT serum levels that could be used as a clinical indicator for judging the severity of scrub typhus, seems to be associated with high mortality of scrub typhus in ICU, but that prefer to a diagnosis of scrub typhus in other patients when PCT $<1.3 \mathrm{ng} / \mathrm{ml}[50,51]$. In this study, the PCT serum levels were significantly higher in acute $\mathrm{Q}$ fever than those in scrub typhus. On one hand, people infected with $C$. burnetti are more likely to suffer toxic hepatitis, which can lead to serum PCT levels increase by the release of more inflammatory factors. On the other hand, there are more non-severe patients in scrub typhus with mild histopathological changes in the liver.

\section{Conclusions}

In summary, this study suggests that more attention should be set on Q fever and mNGS may be a useful method for identity acute $\mathrm{Q}$ fever, especially without traditional culture methods. By compared the clinical features of the two diseases, we can conclude that sex, age, serologic test, and physical examination are important in the differentiation of acute $Q$ fever from scrub typhus. Last but not least, careful physical examination, which can find the eschar, skin rash and lymphadenopathy plays an important role in differentiating acute $\mathrm{Q}$ fever and scrub typhus.

\section{Abbreviations}

\section{C. burnetti}

Coxiella burnetti; $O$. tsutsugamushi:Orientia tsutsugamushi; mNGS:Metagenomic next-generation sequencing; ELISA:Enzyme Linked Immunosorbent Assay; IFA:Indirect Immunofluorescence Assay; PCR:Polymerase Chain Reaction; WBC:White Blood Cell; NEU:Neutrophil; EOS:Eosinophils; PLT:Platelets; ALT:Alanine aminotransferase; AST:Aspartate aminotransferase; T-BIL:Total bilirubin; $\gamma$-GT:Y-glutamyl transpeptidase; ESR:Erythrocyte Sedimentation Rate; CRP:C-reactive protein; PCT:Procalcitonin; SCr:Serum Creatinine;

ARDS

Acute Respiratory Distress Syndrome; GBS:Guillain-Barre syndrome. 


\section{Declarations}

\section{Ethics Statement and Informed Consent}

This study was approved by the institutional review board of the Fifth Affiliated Hospital of Sun Yat-sen University (Zhuhai, P.R. China) (No.ZDWY[2020] Lunzi No. (K19-1)). Waiver of consent was obtained given the observational nature of the project.

\section{Consent for publication}

Not applicable.

\section{Availability of data and materials}

The datasets used and/or analysed during the current study are available from the corresponding author on reasonable request.

\section{Competing interests}

The authors declare that they have no competing interests.

\section{Author Contributions}

Jinyu Xia designed the study. Xi Liu and Ziliang Lin wrote the manuscript. Gongqi Chen, Hongqiong Zhu and Pengyuan He attended patients and provided clinical data. Mingxing Huang performed data analysis.

All authors read and approved the final version of the manuscript.

\section{Funding}

Not applicable.

\section{Acknowledgements}

Not applicable.

\section{Authors' information}

${ }^{1}$ Department of Infectious Diseases, The Fifth Affiliated Hospital of Sun Yat-sen University, Zhuhai, China.

\section{References}

[1] Parker NR, Barralet JH, Bell AM. Q fever. The Lancet. 2006;367(9511):679-88. 
[2] Madariaga MG, Rezai K, Trenholme GM, Weinstein RA. Q fever: a biological weapon in your backyard. Lancet Infect Dis. 2003;3(11):709-21.

[3] Shu-rong Y. Progress in research of Q fever in China. CHINESE JOURNAL OF EPIDEMIOLOGY. 2000(06):56-9.

[4] Tao SLW. Advances on molecular pathogenesis of Coxiella burnetii. Chinese Journal of Zoonoses. 2015;31(09):876-80.

[5] Miller MB, Tang YW. Basic Concepts of Microarrays and Potential Applications in Clinical Microbiology. Clin Microbiol Rev. 2009;22(4):611-33.

[6] Wilson MR, Naccache SN, Samayoa E, Biagtan M, Bashir H, Yu G, et al. Actionable Diagnosis of Neuroleptospirosis by Next-Generation Sequencing. New Engl J Med. 2014;370(25):2408-17.

[7] Ai J, Weng S, Cheng Q, Cui P, Li Y, Wu H, et al. Human Endophthalmitis Caused By Pseudorabies Virus Infection, China, 2017. Emerg Infect Dis. 2018;24(6):1087-90.

[8] Chiu CY, Miller SA. Clinical metagenomics. Nat Rev Genet. 2019;20(6):341-55.

[9] Maurin M, Raoult D. Q fever. Clin Microbiol Rev. 1999;12(4):518-53.

[10] Raoult D, Marrie TJ, Mege JL. Natural history and pathophysiology of Q fever. The Lancet Infectious Diseases. 2005;5(4):219-26.

[11] Badenhorst D, Tatard C, Suputtamongkol Y, Robinson TJ, Dobigny G. Host cell/Orientia tsutsugamushi interactions: Evolution and expression of syndecan-4 in Asian rodents (Rodentia, Muridae). Infection, Genetics and Evolution. 2012;12(5):1136-46.

[12] Basnyat B, Belbase RH, Zimmerman MD, Woods CW, Reller LB, Murdoch DR. Clinical Features of Scrub Typhus. Clin Infect Dis. 2006;42(10):1505-6.

[13] Kim M, Kim S, Choi J, Wie S. Clinical and Laboratory Predictors associated with Complicated Scrub Typhus. Infection \& Chemotherapy. 2019;51(2):161.

[14] Szymańska-Czerwińska M, Galińska EM, Niemczuk K, Knap JP. Prevalence of Coxiella burnetii Infection in Humans Occupationally Exposed to Animals in Poland. Vector-Borne Zoonot. 2015;15(4):2617.

[15] Klemmer J, Njeru J, Emam A, El-Sayed A, Moawad AA, Henning K, et al. Q fever in Egypt: Epidemiological survey of Coxiella burnetii specific antibodies in cattle, buffaloes, sheep, goats and camels. Plos One. 2018;13(2):e192188.

[16] Wegdam-Blans MCA, Wielders CCH, Meekelenkamp J, Korbeeck JM, Herremans T, Tjhie HT, et al. Evaluation of Commonly Used Serological Tests for Detection of Coxiella burnetii Antibodies in Well- 
Defined Acute and Follow-Up Sera. Clin Vaccine Immunol. 2012;19(7):1110-5.

[17] Omsland A, Cockrell DC, Howe D, Fischer ER, Virtaneva K, Sturdevant DE, et al. Host cell-free growth of the $\mathrm{Q}$ fever bacterium Coxiella burnetii. Proceedings of the National Academy of Sciences. 2009;106(11):4430-4.

[18] Fournier PE, Raoult D. Comparison of PCR and Serology Assays for Early Diagnosis of Acute Q Fever. J Clin Microbiol. 2003;41(11):5094-8.

[19] WILKINSON R, ROWLAND D, CHING WM. Development of an Improved Rapid Lateral Flow Assay for the Detection of Orientia tsutsugamushi-Specific IgG/lgM Antibodies. Ann Ny Acad Sci. 2003;990(1):38690 .

[20] Koraluru M, Bairy I, Varma M, Vidyasagar S. Diagnostic validation of selected serological tests for detecting scrub typhus. Microbiol Immunol. 2015;59(7):371-4.

[21] Saisongkorh W, Chenchittikul M, Silpapojakul K. Evaluation of nested PCR for the diagnosis of scrub typhus among patients with acute pyrexia of unknown origin. T Roy Soc Trop Med H. 2004;98(6):360-6.

[22] Clark NJ, Soares Magalhães RJ. Airborne geographical dispersal of Q fever from livestock holdings to human communities: a systematic review and critical appraisal of evidence. Bmc Infect Dis. 2018;18(1):218.

[23] Faix DJ, Harrison DJ, Riddle MS, Vaughn AF, Yingst SL, Earhart K, et al. Outbreak of Q fever among US military in western Iraq, June-July 2005. Clin Infect Dis. 2008;46(7):e65-8.

[24] Anderson AD, Baker TR, Littrell AC, Mott RL, Niebuhr DW, Smoak BL. Seroepidemiologic Survey for Coxiella burnetii Among Hospitalized US Troops Deployed to Iraq*. Zoonoses Public Hlth. 2011;58(4):27683.

[25] Naccache SN, Federman S, Veeraraghavan N, Zaharia M, Lee D, Samayoa E, et al. A cloud-compatible bioinformatics pipeline for ultrarapid pathogen identification from next-generation sequencing of clinical samples. Genome Res. 2014;24(7):1180-92.

[26] Schlaberg R, Chiu CY, Miller S, Procop GW, Weinstock G. Validation of Metagenomic Next-Generation Sequencing Tests for Universal Pathogen Detection. Arch Pathol Lab Med. 2017;141(6):776-86.

[27] Blauwkamp TA, Thair S, Rosen MJ, Blair L, Lindner MS, Vilfan ID, et al. Analytical and clinical validation of a microbial cell-free DNA sequencing test for infectious disease. Nat Microbiol. 2019;4(4):663-74.

[28] Miller S, Naccache SN, Samayoa E, Messacar K, Arevalo S, Federman S, et al. Laboratory validation of a clinical metagenomic sequencing assay for pathogen detection in cerebrospinal fluid. Genome Res. 2019;29(5):831-42. 
[29] Liu Y, Feng D, Suo J, Xing Y, Liu G, Liu L, et al. Clinical characteristics of the autumn-winter type scrub typhus cases in south of Shandong province, northern China. Bmc Infect Dis. 2009;9(1):82.

[30] Wu Y, Qian Q, Zhang W, Magalhaes RJS, Li S, Liu Y, et al. Rapid Increase in Scrub Typhus Incidence in Mainland China, 2006-2014. The American Journal of Tropical Medicine and Hygiene. 2016;94(3):532-6.

[31] Raoult D, Tissot-Dupont H, Foucault C, Gouvernet J, Fournier PE, Bernit E, et al. Q Fever 1985-1998: Clinical and Epidemiologic Features of 1,383 Infections. Medicine. 2000;79(2):109-23.

[32] Leone M, Honstettre A, Lepidi H, Capo C, Bayard F, Raoult D, et al. Effect of Sex on Coxiella burnetii Infection: Protective Role of 17 -Estradiol. The Journal of Infectious Diseases. 2004;189(2):339-45.

[33] Melenotte C, Gay L, Mezouar S, Bardin N, Raoult D, Mège JL. The sexual dimorphism of anticardiolipin autoantibodies in acute Q fever patients. Clin Microbiol Infec. 2019;25(6):761-3.

[34] Mehraj V, Textoris J, Capo C, Raoult D, Leone M, Mege JL. Overexpression of the Per2 Gene in Male Patients with Acute Q Fever. J Infect Dis. 2012;206(11):1768-70.

[35] Mayxay M, Castonguay-Vanier J, Chansamouth V, Dubot-Pérès A, Paris DH, Phetsouvanh R, et al. Causes of non-malarial fever in Laos: a prospective study. The Lancet Global Health. 2013;1(1):e46-54.

[36] Parker NR, Barralet JH, Bell AM. Q fever. The Lancet. 2006;367(9511):679-88.

[37] Paris DH, Jenjaroen K, Blacksell SD, Phetsouvanh R, Wuthiekanun V, Newton PN, et al. Differential patterns of endothelial and leucocyte activation in typhus-like illnesses in Laos and Thailand. Clinical \& Experimental Immunology. 2008;153(1):63-7.

[38] Paris DH, Phetsouvanh R, Tanganuchitcharnchai A, Jones M, Jenjaroen K, Vongsouvath $\mathrm{M}$, et al. Orientia tsutsugamushi in Human Scrub Typhus Eschars Shows Tropism for Dendritic Cells and Monocytes Rather than Endothelium. Plos Neglect Trop D. 2012;6(1):e1466.

[39] Elliott A, Schoenlaub L, Freches D, Mitchell W, Zhang G. Neutrophils Play an Important Role in Protective Immunity against Coxiella burnetii Infection. Infect Immun. 2015;83(8):3104-13.

[40] Jang Y, Shin Y, Jin CE, Koo B, Park SY, Kim M, et al. Molecular detection of Coxiella burnetii from the formalin-fixed tissues of Q fever patients with acute hepatitis. Plos One. 2017;12(7):e180237.

[41] Pellegrin M, Delsol G, Auvergnat JC, Familiades J, Faure H, Guiu M, et al. Granulomatous hepatitis in Q fever. Hum Pathol. 1980;11(1):51-7.

[42] Marrie TJ. Q Fever Pneumonia. Infect Dis Clin N Am. 2010;24(1):27-41.

[43] Eldin C, Mélenotte C, Mediannikov O, Ghigo E, Million M, Edouard S, et al. From Q Fever to Coxiella burnetii Infection: a Paradigm Change. Clin Microbiol Rev. 2016;30(1):115-90. 
[44] Lai C, Chang L, Lin J, Chen W, Wei Y, Chiu C, et al. Clinical Characteristics of Q Fever and Etiology of Community-Acquired Pneumonia in a Tropical Region of Southern Taiwan: A Prospective Observational Study. Plos One. 2014;9(7):e102808.

[45] Edouard S, Djossou F, Abboud P, Demar M, Mahamat A, Raoult D. Comparison between Emerging Q Fever in French Guiana and Endemic Q fever in Marseille, France. The American Journal of Tropical Medicine and Hygiene. 2014;90(5):915-9.

[46] Rhee C. Using Procalcitonin to Guide Antibiotic Therapy. Open Forum Infect Di. 2017;4(1):w249.

[47] Covington EW, Roberts MZ, Dong J. Procalcitonin Monitoring as a Guide for Antimicrobial Therapy: A Review of Current Literature. Pharmacotherapy: The Journal of Human Pharmacology and Drug Therapy. 2018;38(5):569-81.

[48] Schuetz P, Bretscher C, Bernasconi L, Mueller B. Overview of procalcitonin assays and procalcitoninguided protocols for the management of patients with infections and sepsis. Expert Rev Mol Diagn. 2017;17(6):593-601.

[49] Rule JA, Hynan LS, Attar N, Sanders C, Korzun WJ, Lee WM. Procalcitonin Identifies Cell Injury, Not Bacterial Infection, in Acute Liver Failure. Plos One. 2015;10(9):e138566.

[50] Lee C, Hwang J, Lee J, Lee JH. The clinical usefulness of serum procalcitonin level in patients with scrub typhus. The Korean Journal of Internal Medicine. 2017;32(4):761-3.

[51] Li JR, Liu Q, Chen CC, Ma AP. [Association between Severity of Scrub Typhus and Serum Procalcitonin Level]. Zhongguo Yi Xue Ke Xue Yuan Xue Bao. 2018;40(3):334-7.

\section{Figures}




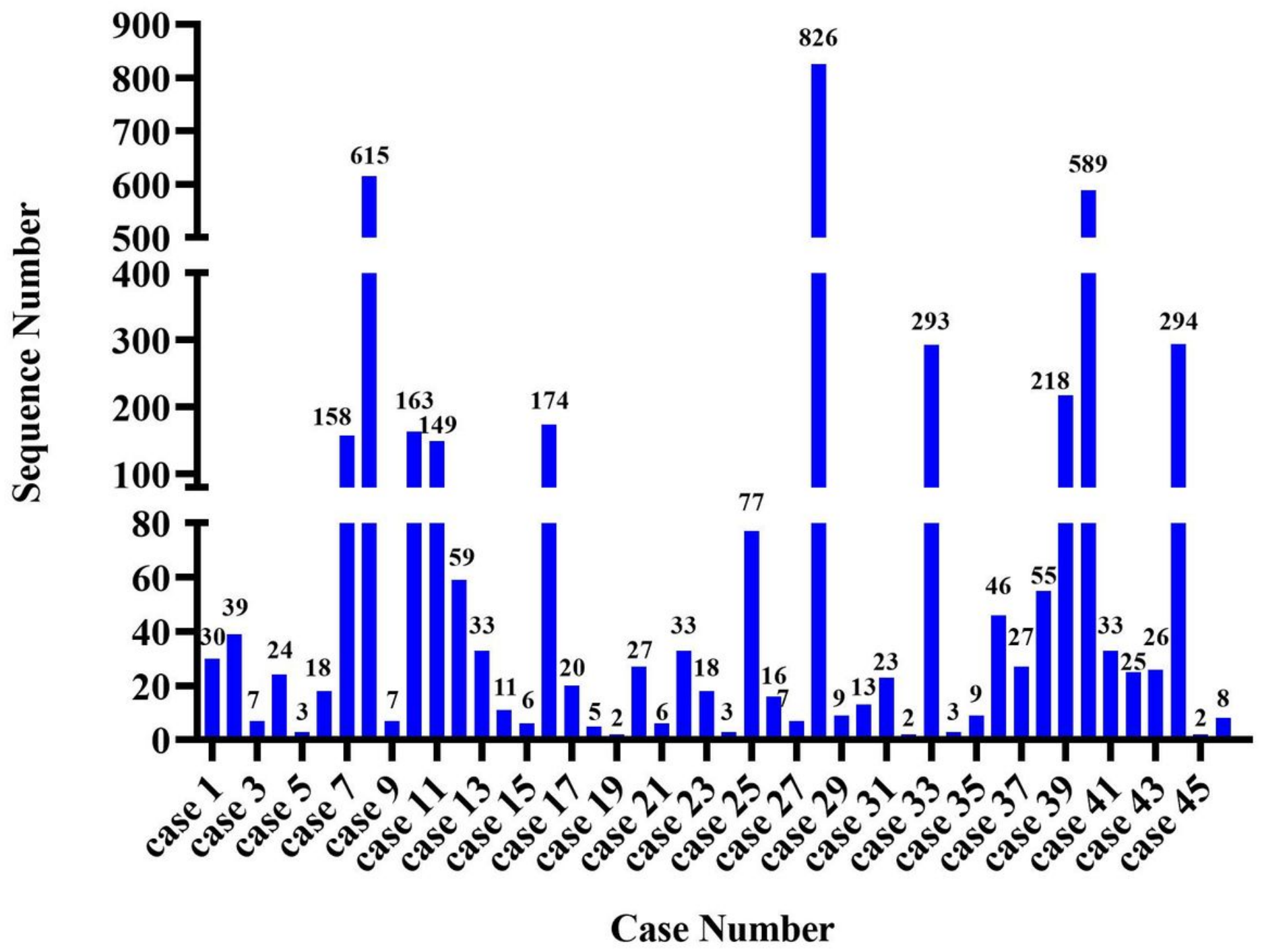

Figure 1

The results of mNGS in acute Q fever. After hospital visit, Blood samples were collected in accordance with standard procedures. All 46 patients be detected varying numbers of pathogen (C. burnetti) sequences from 2 to 826 . 


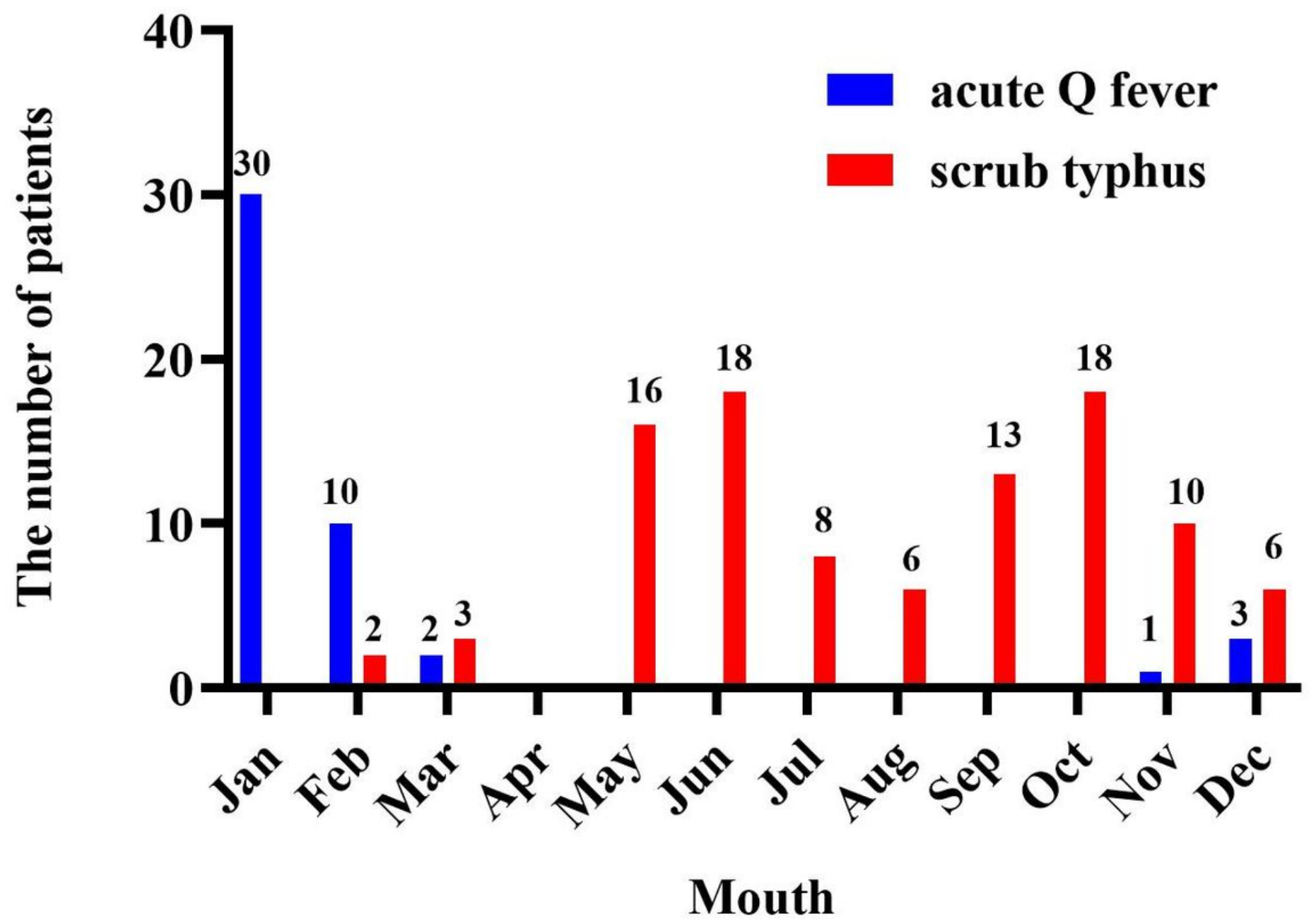

Figure 2

Epidemic trend of tsutsugamushi disease and acute $\mathrm{Q}$ fever. The acute $\mathrm{Q}$ fever cases are detected in January, February, March, November and December, but higher incidence is reported during January to February. However, scrub typhus typically takes place from May to December with two peaks. 